
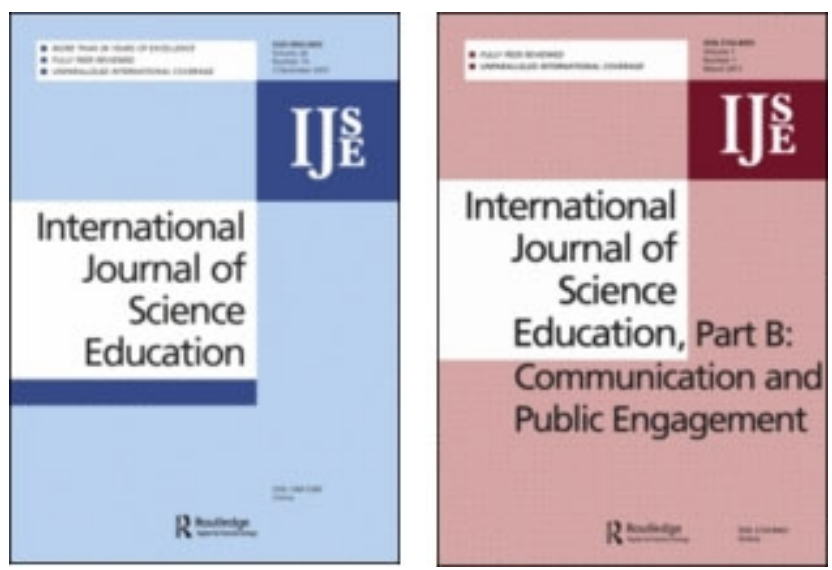

\title{
A Cross-cultural, Cross-age and Cross-gender Study of Hong Kong and UK Secondary Students' Decision Making about a Biological Conservation Issue
}

\begin{tabular}{|r|l|}
\hline Journal: & International Journal of Science Education \\
\hline Manuscript ID & TSED-2018-0427-A.R3 \\
\hline Manuscript Type: & Empirical Research Paper \\
\hline Keywords: & biology education, comparative study, context-based learning \\
\hline Keywords (user): & socioscientific issues \\
\hline \multicolumn{2}{|l}{} \\
\end{tabular}

\section{SCHOLARONE Manuscripts}




\title{
A Cross-cultural Study of Hong Kong and UK Secondary School Students' Decision-Making about a Biological Conservation Issue
}

\begin{abstract}
The possible roles of culture, gender, and age-related factors as mediators of decision making about socioscientific issues (SSIs) have been underexplored, particularly the impact of eross-cultural interactionsdistinct cultural groups' perspectives. This comparative study explored culturally influenced decision-making using a mixed methods approach. To study the impact of culture and cross-cultural understanding on students' decision-making, and how these impacts are possibly mediated by age and gender-related variables, 106 11-13 year old students and 60 15-17 year old students from three Hong Kong schools and four UK schools were engaged in decision-making about shark fishing, framed as an SSI. Data were collected on how students make decisions about the issue before and after interacting with their own peers and considering the views of their international counterparts, using discussion records, supplemented with focus group interviews. The findings show that students associated with the culture of shark eating do not necessarily identify with shark fishing. Three dimensions characterize students' decisions: the human activities to be controlled, the ways to address issues arising from shark fishing, and the concerns underlying students' decisions. Although students showed support for conserving sharks, there were nuanced differences between the two cultural groups in the three decision dimensions, which were possibly mediated by gender and age factors. The findings provide support to the impact of cultural exchange through cross-cultural presentations, post-activity discussion and reflections on their own and others' views on broadening students' perspectives and stimulating their critical reasoning. The study raises some important questions relating to group decision-making about shark conservation.
\end{abstract}

\section{Introduction}

Socioscientific issues (SSIs) are playing an important role in science education as evidenced by the increasing research on students' capacity to engage in decision-making about SSIs. Such ability is regarded as an important part of scientific literacy to allow students to engage "intelligently in public discourse and debate about matters of scientific and technological 
concern" (NRC, 1996, p. 13).

Research indicates that students' various abilities and values underlie the reasoning process behind decision-making about SSIs. These include multi-perspective thinking and science conceptual understanding (e.g., Ratcliffe, 1997; Hogan, 1999), evaluation of evidence (e.g. Sadler, et al., 2004), values and moral or ethical judgement (e.g. Sadler and Zeidler, 2005), and generation of criteria to differentiate among alternatives (Authors, 2012).

Research findings on students' abilities to reason about SSIs are mixed. While some researchers have found that students are able to recognize arguments from social, ecological, economic and scientific perspectives (e.g., Patronis, et al, 1999; Wu and Tsai, 2007), others have shown that students do not intuitively address environmental SSIs from multiple perspectives (e.g., Hogan, 2002; Kortland, 1996). Although variation in the development of epistemological beliefs in SSIs is recognized (Zeidler, et al, 2013), the vast majority of research studies have been targeted at a particular age group drawn from middle school to college students as evident in Sadler's review (2004). A rare example of a singular study involving subjects of different ages was undertaken by Eggert and Bögeholz (2010), who reported that decision-making competence increased with years of education in terms of the use of trade-offs and the ability to weigh decision criteria. There have been more studies on the effect of gender on learning with SSIs than the effect of age. For example, Ottander and Ekborg (2012) reported that girls were more interested in discussing SSIs and considered they learned more through SSIs, which was relevant to their future. Yang (2004) found that in making decisions on environmentally related SSIs, female high school students stressed human feelings more than males, while males tended to emphasise the importance of experts' information to a greater extent. However, Wu and Tsai's (2007) study on the use of nuclear energy, observed no gender differences in terms of construction of supportive arguments, counter-arguments and rebuttals. It is unusual for studies on decision-making about SSIs to compare different gender or age groups in a single study - let alone possible interactions between the two, leaving a gap to be filled in this field of research.

Recognizing decision-making about SSIs as an important means to develop students' scientific literacy (Liu, et al, 2011) and character and value development (e.g. Lee et al, 2013), researchers 
have turned to exploring pedagogical approaches to enhance these processes in the classroom. These approaches include group discussion and cooperative learning (e.g. Day and Bryce, 2013; Maloney, 2007; Author, 2009), strategic training in decision-making strategies (Gresch et al, 2013), using optimization as a reasoning strategy (Papadouris, 2012), transactional argumentation analysis (Rudsberg, K. et al, 2013), and the use of ingenious discussion strategies for widening discussion perspectives (France et al, 2012). Despite this, studies on the influences of cross-cultural interactions on students' decision-making are not common, even though many of these issues transcend national boundaries and necessitate international cooperation for their eventual resolution. We refer to cross-cultural interactions as different forms of exchanges that expose students of a particular culture to the views of their counterparts of other cultures, which may vary from merely learning about these counterparts' views to negotiating with them ways to address the issue in question. This implies the fundamental importance of including a cultural perspective in deliberating SSIs. The lack of emphasis on the influences of cultural contexts in relation to decision-making about SSIs, and the effect of cross-cultural exchanges as a pedagogical approach to enhance students' decision-making on SSIs, does not reflect the real life situation in which consensual decisions underpinned by intercultural understanding are essential to resolving global SSIs.

There are a few studies that point to the potential influences of cultural contexts on secondary school students' decision-making. Authors (2012) explored the influences of contexts on students' decision-making, by comparing how 13-14 year old students in two cities of China - Hong Kong and Guangzhou - differed in their decisions about the issue of whether to impose central slaughtering of chickens to control the spread of avian flu. The results showed marked differences between the two student groups in their decision-making criteria, with Hong Kong students being more concerned with health risks, and Guangzhou students more concerned with maintaining traditional Chinese culture. Moreover, the study revealed that multi-perspective reasoning was enhanced by both intra-contextual class discussion within the same school in each city, and cross-contextual interactions through watching and considering video-recorded presentations of the decisions of peers in the other city. The outcomes indicate more complex decision-making characterized by a greater degree of compromise between conflicting alternatives. 
Beyond contextual influences to cultural influences, Zeidler et al (2013) conducted a study across five different countries exploring culture as a mediator of students' epistemological patterns of reasoning about SSIs. The findings demonstrated cross-cultural congruity in students' conceptualization of fairness in making decisions about the allocation of medical resources, but disparities existed in students' ability to raise scientifically appropriate questions and make use of scientific information to assist them in making decisions.

More recently, Author (2015) conducted a pilot cross-country and cross-cultural study to compare how 16-17-year-old students in England, Germany, Sweden, and Hong Kong engaged in group decision-making about whaling. The findings showed that the Hong Kong students were more tolerant of whaling than their English and Swedish counterparts, with the former putting a dual emphasis on economic and scientific perspectives, whereas the latter focused mainly on scientific and ethical perspectives. The authors postulated these outcomes were due to different cultural contexts, resulting in culture-dependent value judgments.

This study aimed to expand our understanding of cross-cultural decision-making about conservation issues. We set out to explore the possible role of culture, as a mediator of SSI decision-making by secondary school students, and the impact of cross-cultural interactions on the quality of decision-making about shark conservation. Shark conservation has aroused increasing concern as the increased consumption of sharks, particularly their fins, due to rising living standards in Asian countries, has posed a threat to their continued survival. To the best of our knowledge, there have not been cross-cultural studies of this kind that have examined the influence of age and gender on students' decision-making about conservation issues, and how these variables interact with culture in influencing decision-making. A further factor investigated is the effect of differential cultural connection of the issue on students' decision-making. The study also examined the impact of knowing other cultures' views on one's own final decision.

\section{$\underline{\text { Research questions }}$}

1. What effect does culture, age and gender have on students' decision-making about shark fishing? 
2. What impact does an activity involving group discussion and cross-cultural understanding have on students' decision-making about shark fishing?

\section{Methodology}

The participants

Secondary school students in Hong Kong (HK) and the United Kingdom (UK) were selected as the subjects of the study. The first two authors extended invitations to schools in their locations to take part in the study in HK and the UK respectively. It was up to the teachers to select the classes for participation in the study such that there was minimal interference to their teaching schedule. The students were aged 11-13 and 15-17, and are referred to as the junior and senior group respectively. The junior group comprised 2 classes with $59 \mathrm{HK}$ students and 2 classes with 47 UK students; and the senior group comprised 2 classes with $43 \mathrm{HK}$ students and 2 classes with 17 UK students. All the eight classes were from secondary co-educational and public (state) schools. The four classes in Hong Kong were from three schools and the four classes in the UK were from four schools. Most students were average to higher ability in science. The UK students were of mixed ethnicities with very few ethnic Chinese, while the Hong Kong group was ethnic Chinese, which made up about $98 \%$ of the population of the territory. As the sample was necessarily small, the findings were intended to provide insights into our research questions, generating hypotheses worthy for further study. Each class in each school was paired up with a corresponding class of comparable age in the other locality for cross-cultural exchange. Prior consent was obtained from the school, parents and students before the activity, to comply with the ethical requirements of both locations.

\section{The issue}

Shark fishing as a conservation issue was chosen as the focus for discussion and decision-making. Shark fishing is more culturally and economically related to Hong Kong than UK. Shark fins are regarded by the Chinese as a traditional delicacy, commonly consumed on special occasions such as weddings or birthday banquets (Fabinyi, 2011), and it can therefore be regarded as more culturally related to $\mathrm{HK}$ students than to UK students, although Europeans sometimes unknowingly also consume a certain amount of shark meat (Friedrich et al., 2014). This has become a global conservation issue as sharks are hunted all over the world and many shark 
species are declining, threatening their survival. It is increasingly recognized as a problem to which actions such as removal of shark fins from the menu by some HK restaurants have been taken to address the issue. Hence, it is envisaged that this issue might elicit different responses from students in the two locations due to the different cultural relevance of the issue.

\section{The decision-making framework}

In this study, students were encouraged to consider and discuss what should be done about the shark fishing issue through a series of scaffolds. They were first introduced to the issue by providing them with rudimentary facts about sharks and shark fishing with a short video showing the causes and existing status of the issue, but without any suggestion of what actions need to be taken. The same video and information about the issue were provided to all participants including junior and senior ones from both locations. After this, they were asked to consider arguments and evidence relevant to the issue. Secondly, students were asked to discuss the issue in groups as guided by the framework postulated by Svenson (1992, 1996), in which they identified decision alternatives, differentiated those alternatives by weighing the pros and cons, and made the group's decision with justifications. The third phase adopted the idea of post-decision differentiation, engaging students in continuous evaluation of their decisions by drawing on the decisions of their international counterparts from the UK or HK. However, no joint decision-making between the two cultural groups was involved due to time constraints. There were altogether 25 student groups in all the HK schools, with 14 and 11 from the junior and senior classes respectively; and 18 groups on the UK side, with 12 from the junior and 6 from the senior level.

\section{The research design}

Research question 1: A mixed methods approach was used to answer research question 1 to identify patterns and trends in students' decision-making with respect to cultural, age and gender comparisons. The feasibility of this approach has been demonstrated in previous studies (e.g. Authors, 2012; Zeidler et al., 2013; Wu and Tsai, 2007). The intervention engaged students in decision-making about the issue across three lessons. The first lesson took about 45 minutes, and the second and third lessons were each between an hour and 90 minutes. In the first lesson, the teacher provided students with essential background information and data (scientific and 
non-scientific) about the issue, and various stakeholders' views extracted from relevant papers and media reports, to make sure students had at least a basic socioscientific understanding. To ensure consistency of teachers' input in different classes, the teachers involved were provided with a set of instructions for them to brief their students of all age-groups about the issue and guided them to discuss the issue without influencing their decisions. The teacher briefing included the presentation of a short video on the present state of shark fishing and its purposes, and the three questions listed below, which provided scaffolds to guide them towards decision-making about the issue:

1. What arguments about the issue do you think are important?

2. What evidence is there to support these arguments? How do you feel about the evidence?

3. What should be done about the shark fishing issue?

Students answered the questions individually and without conferring. They recorded their initial individual answers on a pre-activity record sheet and these were collected for analysis.

In the second lesson, students were asked to discuss the issue in groups. Each group was asked to discuss the pros and cons of decision alternatives, and then shared their decisions and justifications with the rest of the class by oral presentations, which were video-recorded. In the third lesson, the students in each locality watched the video-recorded group presentations from their international counterparts, after which they returned to their own group to discuss their views again, drawing reference from the views of their international counterparts. Before the lesson ended, each student would form his or her own opinions based on what they gathered from peer interactions within their own class and between different classes. They then recorded their final individual decision on a post-activity record sheet. They were also asked to reflect on factors that might have affected their decisions throughout the three lessons, and record their answers on the post-activity record sheet. With this step-by-step scaffolding, students were increasingly exposed to broader perspectives and a wider range of arguments from peers in their own geographical location and that of their counterparts.

Research question 2: After the group discussion, a focus group interview was conducted for each class to provide in-depth insights into the students' reasoning patterns, and their reflections on the group discussions and exchanges. Hence, there were a total of eight focus groups. These 
semi-structured interviews were based on the following questions:

- How did you feel about making a decision at the beginning?

- How did you find the discussion within your group and the exchange with the students in the other locality? How did it affect your decision-making?

- In light of your exchange with students in the other locality, suggest some factors that might have impacted your views and their views on the issue.

Hence, the students' initial decisions prior to the discussion and their post-activity decisions as recorded in the pre- and post-activity record sheets constituted the data for analysis of the possible effects of age, gender and culture. Students' responses collected from the interviews contributed to data about students' perceptions of the activity.

\section{Methods of analysis}

Students' records of their decisions were subjected to qualitative and quantitative analysis, focusing first on the structure of students' decisions and justifications. Emergent dimensions characterizing the structure of their decisions were identified after careful reading of the students' decision records. Decisions of individual students from different age, gender and cultural groups were then subjected to analysis against each of these dimensions, followed by a systematic categorization of these patterns (Lincoln and Guba, 1985), as elaborated in the results section, to obtain a number of response categories under each dimension. Students' responses in each dimension were then differentiated and coded according to these categories. The first author and a research assistant, did the coding independently, with the initial categories modified as circumstances warranted it. With all the categories under each dimension finalized, coding was repeated to ensure good inter-coder reliability according to the finalized sets of themes. The inter-coder reliability was over $80 \%$ in the final coding, and the differences were resolved by negotiation by considering each other's basis of their categorization so as to reach a mutual agreement of the best way to code the students' responses..

Descriptive statistics, and inferential statistics by means of t-tests, were applied wherever applicable to illuminate any age, gender or cultural differences, and any interactions among these factors. 


\section{$\underline{\text { Results }}$}

The decisions that individual students made as recorded in their pre- and post-activity record sheets were analysed. All students thought that shark fishing was an issue that needed to be addressed. Three dimensions embedded in the structure of their decisions were identified: the human activities to be controlled; the proposed ways of solving the problem; and the students' underlying concerns that constitute the rationale for their decisions. Although not all three dimensions could be identified in all cases, as students were not asked to express their decisions in that particular way, these three dimensions could be delineated in most of the students' responses, thus providing a useful framework for analysing and comparing students' decisions across the cultural groups. Table 1 lists the categories of responses within each dimension. Table 2 shows examples of how student responses were categorized.

\section{Insert Table 1 and 2 here.}

These three dimensions of students' decisions were compared before and after the lessons across age, gender and culture to examine the effect of these demographic variables on students' decision-making. Students' patterns of decision-making within a particular dimension were reflected by the percentages of students in each response category under that dimension. Due to the nature of the data, they could only be analysed using descriptive statistics rather than inferential statistics. However, independent t-tests were used to analyse the average number of response categories coded for a particular student group under each dimension (human activities to be controlled, ways of solving the problem, and underlying concerns) to reflect the range of perspectives students had across different cultural, gender and age groups before or after the activity. The pre- and post-activity changes in these ranges were also compared by paired t-tests to reflect the impact of the activity on students' decisions about shark fishing, and to provide evidence as to whether gender and age played a role in mediating such impacts. The sections below summarise differences in the extent to which the students raised the three dimensions according to cultural group, age and gender.-Due to limitation of limited space, only data for those pairs of groups showing statistically significant differences are shown in the tables provided in

\section{these sections. .}




\section{Dimension 1: Human activities to be controlled}

\section{Cultural differences}

The human activities to be controlled are those leading towards sustaining the shark fishing industry. Three major human activities were identified from the students' responses: shark fishing, consumption of sharks (predominantly shark fins), and trading of sharks. Both before and after the classroom intervention an overwhelming majority of students in all cultural, gender and age groups in both localities (between 73\% and 92\%) targeted the activity of shark fishing, and over $50 \%$ of students in all groups suggested restrictions on shark fishing rather than a complete ban. These restrictions included limiting the frequency of shark fishing and the catch size. Fewer students focused on the consumption of sharks (all less than 30\%), and even fewer on the trading of shark products (all less than 20\%). Before the activity, relatively more UK students $(90 \%)$ targeted shark fishing than their HK counterparts $(70 \%)$, whereas considerably more HK $(27 \%)$ than UK students $(10 \%)$ tended to target consumption of shark. In terms of changed decisions as a result of the activity, more UK students (pre-activity $8 \%$ and post-activity $18 \%$ ) and fewer HK students (pre-activity $27 \%$ and post-activity $16 \%$ ) targeted shark consumption, indicating that the activity served to close the gap between the two cultural groups in this regard.

\section{Gender differences}

In all groups, more female students (17-35\%) than males (0-20\%) targeted shark consumption before the activity, but this number changed after the activity (Female: 14-21\%; male: 15-17\%), thus narrowing the gender gap. Quantitative analysis of the range of human activities that students targeted suggested a gender effect within the UK group but not the HK group. UK female students targeted a wider range of human activities (mean=1.21) than their male counterparts $($ mean $=0.94)$ before the activity, which was statistically significant $(p<0.05)($ Table 3). However, this gender difference was no longer significant after the activity.

\section{Age differences}

Age differences also manifested themselves differently across the two cultural groups. Post-activity, HK juniors were more inclined to target shark fishing (pre-activity $71 \%$ and 
post-activity $89.8 \%$ ), while the change was less obvious for their UK counterparts (pre-activity $95.6 \%$ and post-activity $84.4 \%$ ). This trend was less noticeable in the senior group. As to the range of human activities to be controlled, junior students as a whole (1.22) showed a significantly greater mean number than their senior counterparts $(0.98)(p<0.05)$. This difference was mainly due to the large difference between the two age groups in HK (Junior=1.31; Senior $=0.88)(\mathrm{p}<0.01)($ Table 3$)$.

Insert Table 3 here.

Dimension 2: Ways of solving the problem

Cultural differences

All students suggested ways to reduce the problem, that is, the threat to shark populations. Students' suggested ways of solving the problem fell into four main categories: legislative control, educational solutions, using shark substitutes, and artificial breeding of sharks (Table 4). Both before and after the activity, UK and HK students supported imposing legislative control on shark fishing to a greater extent than any other means. Although more HK than UK students suggested education solutions both before and after the activity, post-activity UK students were more inclined to support educational means (from $7 \%$ before to $24 \%$ after). More students from both cultural groups mentioned shark breeding to address the problem after the activity (18-21\%) than before (7\%), and slightly more UK students opted for using shark fin substitutes after the activity.

\section{Insert Table 4 here. Gender and age differences}

Gender differences were observed within individual cultural groups. Before the activity, HK females showed a significantly higher mean for an Education solution than males (47\% and 22\% respectively), but this gap disappeared after the activity (30\% and $37 \%$ respectively). As shown in Table 5, in both locations, both before and after the activity, senior students on average suggested more ways of solving the problem (1.85) than junior students (0.92), and this difference was significant $(\mathrm{p}<0.001)$. Within the senior groups, HK females showed a significantly greater mean (2.25) than UK females (1.36) before the activity $(\mathrm{p}<0.05)$; and in the junior groups, HK males had a mean score (1.39) significantly greater than UK males (0.93) after 
the activity $(\mathrm{p}<0.05)$. These data suggest gender interacting with culture and age in impacting on students' choice of ways for shark protection. While more post-activity students identified Education as a way of solving the problem, this change was particularly prominent among UK senior students (pre-activity $12 \%$ and post-activity 59\%). On the whole, there was a downward trend for legislative means of control.

Insert Table 5 here.

Dimension 3: Concerns underlying students'decisions

\section{Cultural differences}

Four major concerns were embedded in the students' decisions: protection of sharks for sustainability; animal rights; sharks as a cultural food source; and economic concerns including employment of workers in the trade. At the beginning of the activity, the most often cited concern by students in both cultural groups was to protect sharks somehow, to address the decreasing shark population ( $41 \%$ for $\mathrm{HK}$ and $44 \%$ for UK). The concern categorized as 'the protection of sharks for sustainability' actually comprises student responses in varying detail ranging from reversing the decreasing shark populations to allowing sharks to reproduce, protecting shark species from extinction, avoiding damage to nature or maintaining a balanced ecosystem. These responses came as a continuum, which does not enable them to be unequivocally differentiated into sub-categories. This was followed by the concern with sharks as cultural food sources ( $11 \%$ for UK and $34 \%$ for HK). After the activity, more UK students gave consideration to sharks as a cultural food source (pre-activity $11 \%$ and post-activity $19 \%$ ). Within the HK group, after going through the activity, the general concern with the protection of sharks increased rather markedly (from $41 \%$ to $57 \%$ ).

\section{Gender and age differences}

Gender differences were not obvious with respect to the type of students' concerns and the range of concerns, except that HK males showed a significantly wider range of concerns (1.08) than UK males $(0.58)$ after the activity $(\mathrm{p}<0.01)($ Table 6). Senior students considered a significantly wider range of concerns than their junior counterparts before (senior 1.18 ; junior $0.74 ; \mathrm{p}<0.001$ ) 


\section{Findings from the student interviews}

All focus group interviews were transcribed. The identification of issues that struck the interviewees allowed exploration of students' thinking about important aspects of the decision-making process and qualitative comparison across the two cultural groups.

\section{Perceived factors affecting the students' decision-making}

Students were asked at the end of the activity what factors might have impacted their views and the views of other students on the issue. Their responses could be categorized into two types: i) responses related to aspects of the decision-making activity, and ii) responses related to aspects of the issue. More HK students (61\%) than UK students (17\%) tended to focus on the second category (e.g. ecological, economic or cultural aspects), while the opposite was true for the first category. Under the first category, more UK students than HK students considered the 
information provided at the start of the activity more of a helpful influence $(34 \%$ and $7 \%$ respectively), they found the cross-cultural sharing to be influential ( $24 \%$ and $9 \%$ respectively), and they mentioned how the activity had encouraged them to think more deeply and broadly (28\% and 15\% respectively). However, more HK students $(21 \%)$ than UK students (11\%) found peer influences to be important.

\section{Perceived challenges to students' decision-making}

While reflecting on the issues and classroom activities, students raised two main challenges they encountered in their decision-making:

i) The challenge of evaluating different stakeholders' interests. All focus groups in both localities raised the difficulty they experienced in evaluating the diverse views of stakeholders, as illustrated by the following interview extracts:

"I think also it showed how difficult it is to actually make a decision, to actually make everybody happy, and also probably it makes us understand why something hasn't been done about it already, because I think probably nobody knows the answer to it." (Victoria, UK senior female)

"It is hard to make a choice. We know conservation of sharks is a good thing, but it will also cause other people to oppose it, because the Chinese people focus on traditional culture. They think eating shark fins is a symbol of reputation." (Man, HK senior male)

\section{ii) The challenge of collective decision-making}

Students discussed the challenges they faced in group decision-making, the biggest of which appeared to be the difficulty in reaching a consensus acceptable to all members of the group.

"I found it also quite difficult though, because we actually had in our group differing opinions on things. So we kind of had to make an ultimatum on the decision."(Clare, UK senior female)

"There are difficulties in the process. The group-mates have different views, and I felt difficult to analyse which is the best solution." (Chang, HK junior male) 


\section{Perceived impact of the cross-cultural exchange on students' decision-making}

However, interactions within and among groups helped some students to arrive at more informed decisions, as illustrated by the following interview extracts:

"Well I think in our group we all kind of thought the same thing. So we didn't really think much about what other people have said, but as the lesson went on, we kind of all started having our own opinions on things. So then we kind of then thought 'Oh yeah, they think that, so that might be a good option." (Nick, UK junior male)

"After these three lessons, I think my current solution is better than that in the first lesson. It is more effective. I have more confidence after listening to the views of others and do the reflection, then my solution will be more comprehensive."(Fan, HK senior male)

The students raised three main areas of impact that the cultural exchange had on their decision-making process: broadening their perspectives on the issue; providing a context for critical thinking about different arguments; the enhanced awareness of culture as a factor impinging on decision-making.

\section{i) Broadening of students' perspectives on the issue}

Some students mentioned that the activity increased their awareness and knowledge of the issue and better understood its multifaceted nature, as exemplified by the following interview extracts:

"I never knew about like Hong Kong eating shark fins, or like the other countries trading them. So it was a new topic for me."(Eleanor, UK junior female)

"We should protect the shark. Although it can be used to make a lot of products, we should find other substitutes to avoid the extinction of sharks."(Tong, HK senior male)

Many students referred specifically to the impact of the exchange of views with their cultural counterparts:

. "I also felt their ideas were more creative because they thought about shark fin prosthetics and vegetarian options as an alternative. Whereas we just spoke on the morals of it, and the ethics." (Alisha, UK senior female) 
"Yes, British students offer a lot of innovative ideas, such as patrolling the waters. HK students did not consider the problem of implementation, and their views can inspire us to think some innovative ways to limit shark fishing. "(Suk, HK senior female)

\section{ii) Providing a context for critical thinking}

The process of listening to the views of another culture provided a context for students to view their cultural counterparts' perspectives through a critical lens, and to judge whether those perspectives are justifiable. Students not only reflected on the adequacy of evidence as backing for one's argument and whether or not a particular idea would work, but also highlighted the differential perceptions and arguments of the two cultural groups and how these differences could be reconciled for improving their proposed actions.

"I think their points are like very valid, like it would be an easier way, like say in some places you are not allowed to fish in for so many years. But at the same time, they might not work as - where you could like - one fish would be populated, they may not repopulate quick enough." (Les, UK junior male)

"I believe that their points weren't broad. Like they're all close together, like, we were thinking outside the box at the same time....Like we talked about educating in schools, and like targeting it from the inside, and not just it becoming illegal or laws or anything like that or new hooks. Those are all mainly to do with like government tool things. But we believe that you can't solely leave it up to the Government, where the Government probably is part of the problem at the same time." (Steve, UK senior male)

"Compared with UK students, we both had our own good arguments. I would like to adopt its advantages to improve my plans. This activity can develop my critical thinking, and reflect on the effectiveness of those policies from the perspective of different stakeholders to see whether it can be implemented." (Ching, HK senior female)

“They [UK students] overlooked the situation of the fishermen.” (Ying, HK junior female).

iii) Enhanced awareness of culture as a factor impinging on decision-making 
By contrast, a rather common view among HK students seemed to be that the decisions of their UK counterparts might be limited by their lack of understanding of the Chinese culture. “...because they do not eat sharks fins, so they do not understand this matter."(Yee, HK junior female)

"They do not have this traditional culture, so it is easier for them to come up with solutions." (Hau, HK senior male)

\section{$\underline{\text { Discussion }}$}

\section{Effects of culture, age and gender}

The three dimensions characterising the students' decisions, which have been identified in this study - the stakeholders targeted, the ways of solving the problem, and the students' underlying concerns - could provide a useful framework for analysing decision-making by students about shark fishing, or a similar type of conservation issue with regard to cultural, gender and age differences. Both HK and UK students targeted shark fishermen to a far greater degree than consumers or traders. Legislative control appeared to be the most common means of solving the problem, although students tended to shift to educational solutions after the activity. Ecological concerns were the most common rationale underlying students' decisions within both cultural groups, followed by cultural and economic concerns. 
Overall, both cultural groups shared similar patterns in their decisions about shark fishing. This shows that students do not necessarily identify with their own culture (in this case shark fin consumption in HK) in making decisions about conservation issues. The need to conserve wildlife seems to have gained a foothold within the younger generation across both cultures. The environmental stigma attached to shark fin consumption might explain why HK students, despite their cultural links with shark fishing, did not appear to show stronger identification with or support for this practice than UK students. Despite these commonalities, there are variations between the two cultural groups. Before the activity, more UK students were inclined to control fishing than their HK counterparts, whereas more HK than UK students tended to target consumption of shark fins; and HK students favoured educational means to a far greater extent than UK students. More HK students cited the consumption of sharks as a cultural food source in their decision-making compared with their UK counterparts. However, this does not mean the HK students agreed with shark consumption, but rather they were taking cultural contexts into consideration in deciding how to address the issues. Furthermore, HK students showed a wider range of concerns than UK students both before and after the activity. This might be explained by HK students' heightened awareness of shark fishing due to the perceived relevance of the issue to their own culture, and the controversy about shark fishing, fuelled by the advocacy of environmental protectionists to eliminate shark fins from Chinese banquets (Shark Savers, 2011). Age seems to have an effect, particularly in respect of the ways of solving the problem, with many more senior students considering Education than junior students. Senior students also exhibited significantly more ideas to solve the problem both before and after the activity.

From the interview findings, UK students seemed to have little knowledge about the issue of shark fishing. This echoes Friedrich et al.'s (2014) findings that many UK students were not aware that sharks were commercially fished in European seas, and that shark meat was consumed in the UK. Many of them thought shark consumption is associated only with the UK's Asian community. The authors advocated better public understanding of shark conservation issues by engaging citizens through labelling of products derived directly or indirectly from sharks. 
Although many of the participants expressed concerns about the potential ecological impacts of shark fishing, there was a relative lack of in-depth or explicit references to science among both HK and UK students, in the concerns they expressed and the additional information they suggested should be provided. This sparse reference to science, means it is not certain whether senior students utilized scientific knowledge more than junior students in their decision-making about shark fishing, but a substantial proportion of students were seemingly content with the knowledge provided. These findings seem to echo O'Bryhim and Parsons' (2015) assertion that age and education level make little difference to people's knowledge about the role of sharks as top consumers in the marine ecosystem, as well as reports that that students' ability is limited in applying science in SSI discussions (Jimenez-Aleixandre et al., 2000; Kolsto, 2001, Ratcliffe, 1997). The possible reasons for such limitation of students' ability will be discussed in the conclusion and implications section.

\section{Impact of the activity on students' decision-making about shark fishing}

The existence of changes between respondents' pre and post-activity decisions, indicates that the activity had exerted an impact on the students' decisions. After the activity, there was also a statistically significant increase among UK students in their range of ways of solving the problem, possibly due to an increased understanding of the issue of shark fishing, as revealed by the interviews. Moreover, the findings imply possible mediating effects of both age and gender on the impact of the activity on students' decision-making in both cultural groups. For instance, after the activity, a much greater proportion of UK senior students identified Education as a way of solving the problem. HK junior students showed a wider range of concerns and means of solving the problem, and the increased inclination to target shark fishing by the HK group was more conspicuously shown by the junior group than by the senior group, and by females compared to males. Whether such changes were due to the within-culture group discussion or cross-culture exchange is not certain, but the interview data showed that the latter had exerted at least some influence, especially among the UK students, who reported cross-cultural sharing as an important factor affecting their decisions.

Compared with the HK students, UK students, despite not perceiving the issue as relevant to their culture, seemed to be more sympathetic toward cultural and economic concerns after the 
activity than they did before. This seemed to contradict the findings on UK and HK 16-17 year old students' attitudes towards whaling as reported by Authors (2015). In the case of whaling, which also has no direct link with the UK, Authors (2015) found that UK students were less accepting than HK students toward commercial and research whaling. This implies that students' decisions about conservation of animals are dependent upon the type of animals in question, and their attitudes toward particular species. As concluded by Evagorou et al (2012) from their findings that students' identification with the 'actors' of the issue is important in their decision-making, the following utterances by two junior UK students may provide insights into their perceived difference between sharks and whales:

"Cos sharks are predators and they would eat people but at the same time, they're still a species." (Chris, UK junior male)

“...but it's stereotypical for sharks to eat us, not like...shark er we eat sharks, so yeah” (Donna, UK junior female

\section{Conclusion and implications}

In the present study, students from the two locations did not differ in their patterns of decisions in broad terms, even though HK students are culturally linked to shark fin consumption. This reflects a growing view that the younger generation in HK has become aware of the issue of shark conservation as brought about by their culinary culture. There were some noticeable patterns of changes to students' decision-making after going through the activity. These include reciprocal changes in certain sub-categories under each decision dimension, implying mutual influences of the two cultural groups possibly as a result of enhanced cross-cultural understanding, and the mediating effects of gender and age on the impact of the activity on the two cultural groups. The findings appear to suggest that the impact of the activity was more conspicuous among HK junior students and UK senior students than other sub-groups. HK students showed a significant increase in both their ways of solving the problem and their underlying concerns after the activity, while UK senior students showed a marked increase in their ways of solving the problem after the activity. 
The third challenge arises at the cultural level. In this study, students from both locations were exposed to the views of students from another culture with different degrees of association with the issue. Subsequent to the group discussion and cultural exchange, students' decisions had changed to varying degrees, possibly taking into account their peers' views. More UK students showed considerations of cultural concerns about an issue hitherto unknown to them. The challenge to students at this level is how far culture needs to be considered as a mitigating factor in decision-making about conservation issues with a global impact. Again, the decision needs to be criteria or value-based to assist students in weighing alternatives.

Achieving a better understanding of the views of different cultures with different connections to any conservation issue in question, and the rationale for such views, can be argued as the first step to resolving global issues- which entails international efforts. Opportunities could be provided for different cultures to be exposed to the issue and its cultural roots, and to come together to resolve their differences. The present study shows a way of how this could be done, with evidence of impact on students of different ages, genders and cultures in terms of their understanding of the issue and perspectives for consideration. It is important to take such factors into consideration in developing pedagogical approaches to SSI education at different stages of 
schooling. This kind of SSI-oriented activity emphasizing open discussion and cross-cultural exchange has a natural appeal to students because of its novelty. As a UK junior student put it,

\section{"And it was like different to what we do in like normal school, and yeah, it was cool."}

However, for this kind of pedagogical approach to produce sustainable and transferrable impact, more thought needs to be given to develop students' ability to make informed decisions. The present study points to the desirability to promote their understanding of the nature of conservation issues and scientific knowledge of the role of animals in the ecosystem, their ability to reason critically through different perspectives, their underlying values with a view to developing informed criteria for making decisions, and their sensitivity to the cultural roots of the issues and the complexity that needs to be dealt with in resolving the issue. Research has already indicated, "people with more knowledge pertaining specifically about sharks had potential behaviours more supportive of their conservation" (O’Bryhim and Parsons, 2015, p. 1). A previous study by Tsoi et al (2016) has already pointed to the lack of sufficient knowledge among 11 to 12-year-old HK primary students, and their misconceptions about the significance of sharks in the marine ecosystem. This study further suggests that secondary students did not seem to have gained much progress in developing knowledge in this aspect. Hence, there is a case for science lessons to address biological conservation in a more systematic and in-depth way. The students' general and superficial understanding of scientific knowledge about conservation, derived probably from the media coverage of conservation issues, can be used as a starting point for constructing more complex ecological concepts. Issues that could lead students to informed decision-making could be used as a context, with more background scientific information provided, to deepen students' understanding of ecological knowledge through data analysis and construction of evidence-based arguments. As informed by the findings of this study, with respect to the difference in the factors HK and UK students perceived to be influential to their decision-making, there may be a need for a slight differentiation in the approaches used for students from different cultures. For students who are culturally related to an issue, it may be more helpful to deepen their understanding of the various relevant perspectives, and the relative importance of these perspectives based on value and practical considerations, and to encourage critical reflection on one's cultural perspectives in relation to those of others. 


\section{References}

Barney, E.C., Mintzes, J., \& Yen, C. (2005). Assessing knowledge, attitudes, and behaviour toward charismatic megafauna: the case of dolphins. Journal of Environmental Education, 36, 41-55.

Day, S. P., \& Bryce, T. G. K. (2013). The benefits of cooperative learning to socio-scientific discussion in secondary school science. International Journal of Science Education, 35(9), 1533-1560.

Eggert, S., \& Bögeholz, S. (2009). Students' use of decision-making strategies with regard to socioscientific issues: An application of the Rasch Partial Credit Model. Science Education, 94, 230-258.

Evagorou, M., Jimenez-Aleixandre, M. P., Osborne, J. (2012). 'Should we kill the grey squirrels?' A study exploring students' justifications and decision-making. International Journal of Science Education, 34(3), 401-428.

Fabinyi, M. (2011). Historical, cultural and social perspectives on luxury seafood consumption in China. Environmental Conservation, 39(1), 83-92.

Fabinyi, M., and Liu, N. (2014). Seafood banquets in Beijing: Consumer perspectives and implications for environmental sustainability. Conservation and society, 12(2), 218-228.

Fleming, R. (1986). Adolescent reasoning in socio-scientific issues. Part II: Nonsocial cognition. Journal of Research in Science Teaching, 23, 689-698.

France, B., Mora, H. A., Bay, J. L. (2012). Changing perspectives: Exploring a pedagogy to 
examine other perspectives about stem cell research. International Journal of Science Education, 34(5), 803-824.

Friedrich, L. A., Jefferson, R., and Glegg, G. (2014). Public perceptions of sharks: Gathering support for shark conservation, Marine Policy, 47 (2014), 1-7.

Author (2009). Developing high quality decision-making discussions about biological conservation in a normal classroom setting. International Journal of Science Education, 31(4), 551-570.

Authors (2015). Student decision making about a globally familiar socio-scientific issue: the value of sharing and comparing views with international counterparts. International Journal of Science Education, 37(11), 1855-1874.

Author (2002). The science and values that young people draw upon to make decisions about biological conservation issues. International Journal of Science Education, 24(11), 1157-1169. Gresch, H., Hasselhorn, M., \& Bögehoz, S. (2013). Training in decision-making strategies: An approach to enhance students' competence to deal with socio-scientific issues. International Journal of Science Education, 35(15), 2587-2607.

Hogan, K. (2002). Small groups' ecological reasoning while making an environmental management decision. Journal of Research in Science Teaching, 39, 341-368.

Jimenez-Aleixandre, M.-P., Rodriguez, A. B., \& Duschl, R. A. (2000). "Doing the lesson" or "doing science": Argument in high school genetics. Science Education, 84, 757-792.

Kolstø, S. D. (2001). To trust or not to trust,...' - pupils' ways of judging information encountered in a socio-scientific issue. International Journal of Science Education, 23(9), 877-901

Kortland, K. (1996). An STS case study about students' decision-making on the waste issue. Science Education, 80, 673-689.

Authors (2012). Students' reasoning and decision making about a socio-scientific issue: A cross-context comparison. Science Education, 96. 787-807

Lee, H., Yoo, J., Choi, K., Kim, S-W., Krajcik, J., Herman, B. C., \& Zeidler, D. L. (2013). Socioscientific issues as a vehicle for promoting character and values for global citizens. International Journal of Science Education, 35(12), 2079-2113.

Liu, S-T, Lin, C-S, \& Tsai, C-C. (2011). College students' scientific epistemological views and thinking patterns in socioscientific decision making. Science Education, 95, 497-517.

Maloney, J. (2007). Children's roles and use of evidence in science: an analysis of decision-making in small groups. British Educational Research Journal, 33(3), 371-401.

Means, L. M., \& Voss, J. F. (1996). Who reasons well? Two studies of informal reasoning among children of different grade, ability, and knowledge levels. Cognition and Instruction, 14(2), 139-178.

National Research Council (NRC) (1996). National science education standards. Washington, DC: National Academy Press.

O’Bryhim, J. R. \& Parsons, E.C.M. (2015). Increased knowledge about sharks increases public concern about their conservation. Marine Policy, 56(2015), 43-47.

Ottander, C., \& Ekborg, M. (2012). Students' experience of working with socioscientific issues a quantitative study in secondary school. Research in Science Education, 42, 1147-1163.

Papadouris, N. (2012). Optimization as a reasoning strategy for dealing with socioscientific decision-making situations. Science Education, 96, 600-630.

Patronis, T., Potari, D., \& Spiliotopoulou, V. (1999). Students' argumentation in decision-making on a socio-scientific issue: Implications for teaching. International Journal of 
Science Education, 21, 745-754.

Ratcliffe, M. (1997). Student decision-making about socio-scientific issues within the science curriculum. International Journal of Science Education, 19(2), 167-182.

Rudsberg, K., Öhman, J., \& Östman, L. (2013). Analyzing students' learning in classroom discussions about socioscientific issues. Science Education, 97, 594-620.

Sadler, T. D. (2004). Informal reasoning regarding socioscientific issues: A critical review of research. Journal of Research in Science Teaching, 41(5), 513-536.

Sadler, T. D., Chambers, F. W., \& Zeidler, D. L. (2004). Student conceptualizations of the nature of science in response to a socio-scientific issue. International Journal of Science Education, 26(4), 387-409.

Sadler, T. D., \& Zeidler, D. L. (2005). Patterns of informal reasoning in the context of socioscientific decision-making. Journal of Research in Science Teaching, 42, 112-138.

Shark Savers (2011). Shark fin soup campaign [www document]. URL http://www.sharksavers.org/en/sharkfinsoup.html

Svenson, O. (1992). Differentiation and consolidation theory of human decision making: A frame of reference for the study of pre- and post-decision processes. Acta

Psychologica, 80, 143-168.

Svenson, O. (1996). Decision making and the search for fundamental psychological regularities:

What can be learned from a process perspective? Organizational Behaviour and Human Decision Processes, 65, 252-267.

Tsoi KH, Chan SY, Lee YC, Ip BHY, Cheang CC (2016) Shark Conservation: An Educational Approach Based on Children's Knowledge and Perceptions toward Sharks. PLoS ONE 11(9): e0163406. https://doi.org/10.1371/journal.pone.0163406

Thompson, T., \& Mintzes, J. (2002). Cognitive structure and the affective domain: on knowing and feeling in biology. International Journal of Science Education, 24, 645-660.

Wu, Y.-T., \& Tsai, C.-C. (2007). High school students' informal reasoning on a socioscientific issue: Qualitative and quantitative analyses. International Journal of Science Education, 29(9), 1163-1187.

Yang, F-Y. (2004). Exploring high school students' use of theory and evidence in an everyday context: the role of scientific thinking in environmental science decision-making. International Journal of Science Education, 26(11), 1345-1364.

Zeidler, D. L., Walker, K. A., Ackett, W. A., \& Simmons, M. L. (2002). Tangled up in views: Beliefs in the nature of science and responses to socioscientific dilemmas. Science Education, 86, 343-367

Zeidler, D.L., Herman, B., Ruzek, M., Linder, A. \& Lin, S.S. (2013). Cross-Cultural Epistemological Orientations to Socioscientific Issues. Journal of Research in Science Teaching, 50(3), 251-283

Zohar, A., \& Nemet, F. (2002). Fostering students' knowledge and argumentation skills through dilemmas in human genetics. Journal of Research in Science Teaching, 39(1), 35-62. 
Commented [GM1]: Activity

\begin{tabular}{|c|c|c|}
\hline $\begin{array}{l}\text { Human activity to be } \\
\text { controlled }\end{array}$ & Ways of solving the problem & Underlying concern \\
\hline $\begin{array}{l}\text { Shark fishing } \\
\text { Consumption of sharks } \\
\text { Trading of sharks }\end{array}$ & $\begin{array}{l}\text { Legislation (fishing, } \\
\text { consumption, } \\
\text { restauranteering/trading) } \\
\text { Education (general public, } \\
\text { traders, fishermen, } \\
\text { consumers, } \\
\text { traders/restaurateurs } \\
\text { Others (e.g. improving } \\
\text { fishing technology to } \\
\text { minimize by-catch, } \\
\text { substituting shark } \\
\text { fins/meat/medicine with } \\
\text { other substitutes, breeding } \\
\text { of sharks/Shark farming }\end{array}$ & $\begin{array}{l}\text { Protection of sharks for } \\
\text { sustainability (increasing } \\
\text { the shark populations, } \\
\text { making shark populations } \\
\text { sustainable, protecting } \\
\text { endangered species from } \\
\text { extinction, maintaining } \\
\text { balance of nature or } \\
\text { balance of ecosystem, } \\
\text { avoiding damage to food } \\
\text { chains, etc.) } \\
\text { - Animal rights } \\
\text { - Cultural concern/cultural } \\
\text { food source } \\
\text { Economic/employment } \\
\text { issues } \\
\text { Others (e.g., political } \\
\text { concerns) }\end{array}$ \\
\hline
\end{tabular}

Table: 1: Categorization of students' decisions within the three dimensions

\begin{tabular}{|c|c|c|c|}
\hline \multirow{2}{*}{$\begin{array}{c}\text { Example of student's } \\
\text { decision }\end{array}$} & \multicolumn{3}{|c|}{ Dimension } \\
\hline & $\begin{array}{l}\text { Human activity to } \\
\text { be controlled (B) }\end{array}$ & $\begin{array}{l}\text { Ways of solving } \\
\text { the problem (W) }\end{array}$ & $\begin{array}{l}\text { Underlying concerns } \\
\text { (C) }\end{array}$ \\
\hline 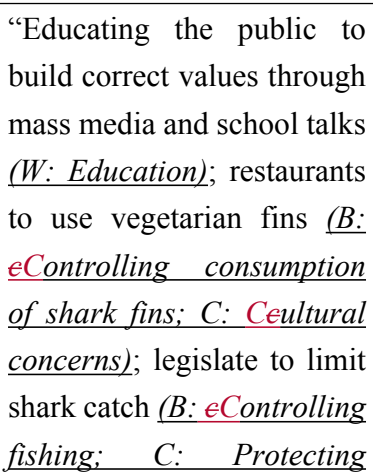 & 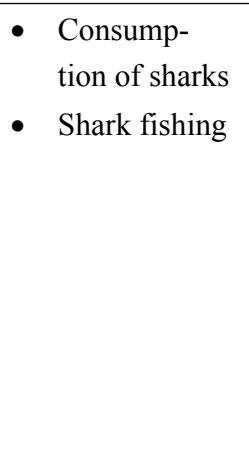 & $\begin{array}{ll}\text { - } & \text { Education } \\
\text { - } & \text { Scientific } \\
& \text { research and } \\
& \text { technology }\end{array}$ & $\begin{array}{l}\text { - Protection of sharks } \\
\text { for sustainability } \\
\text { - Cultural concerns }\end{array}$ \\
\hline
\end{tabular}




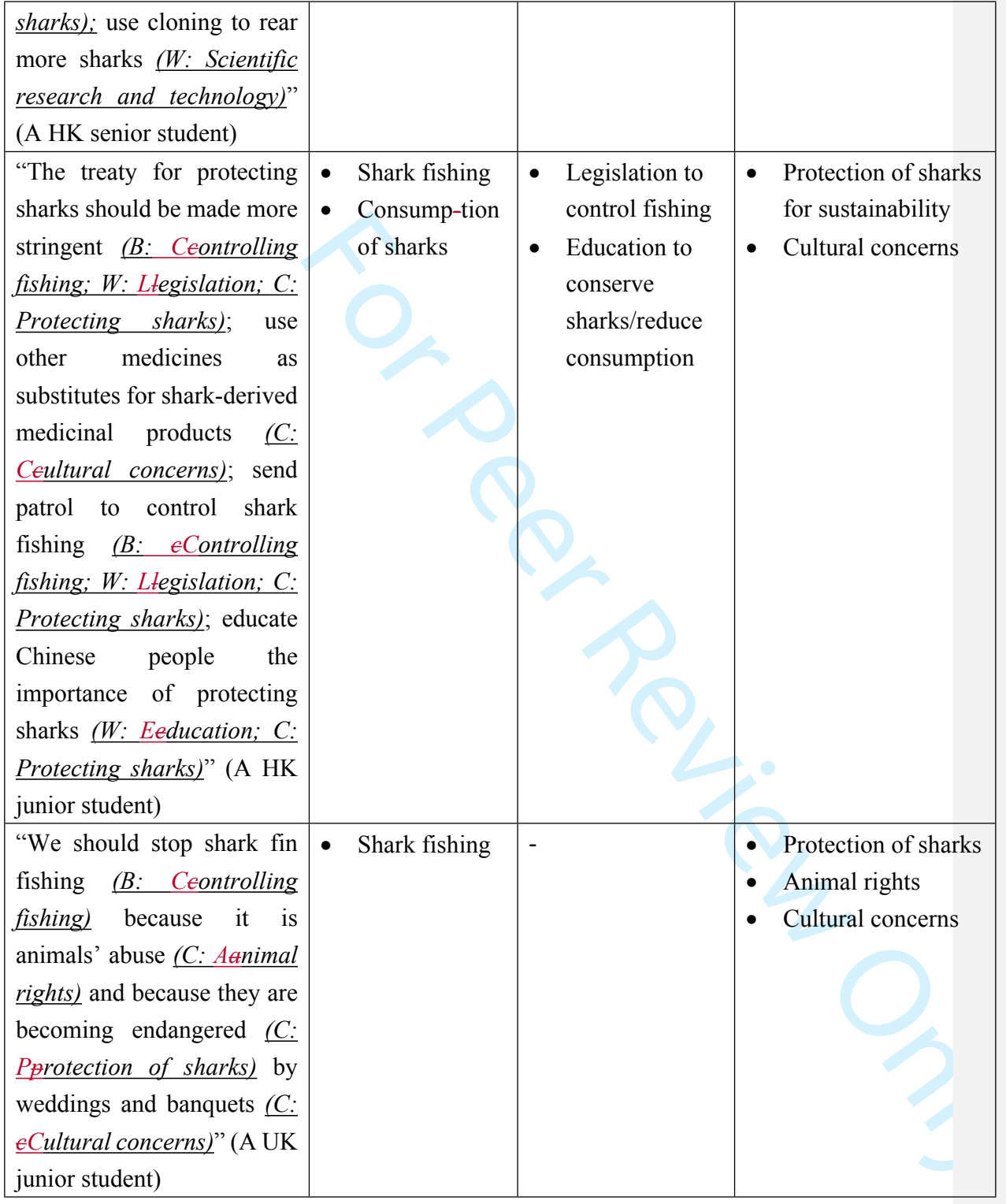

Table 2: Examples of coding of student responses to different categories under the three dimensions

(The words that are underlined and in italics are inserted to show how student responses were coded under the three dimensions.) 


\begin{tabular}{|l|l|l|l|l|l|}
\hline & Group & Mean & SD & t value & Cohen's d \\
\hline $\begin{array}{l}\text { Number of human activities to be } \\
\text { controlled per student } \\
\text { (Before activity) }\end{array}$ & UK Female & 1.21 & 0.41 & $2.50^{*}$ & 0.64 \\
\hline UK Male & 0.94 & 0.43 & & \\
\hline $\begin{array}{l}\text { Number of human activities to be } \\
\text { controlled per student } \\
\text { (After activity) }\end{array}$ & Junior & 1.22 & 0.57 & $2.39^{*}$ & 0.38 \\
\cline { 2 - 6 } & Senior & 0.98 & 0.68 & & \\
\hline & HK Junior & 1.31 & 0.65 & $3.29^{* *}$ & 0.67 \\
& HK Senior & 0.88 & 0.63 & & \\
\hline
\end{tabular}

$$
* \mathrm{p}<.05 ; \quad * * \mathrm{p}<.01
$$

Table 3: Differences between different age, gender and locality groups in the number of human activities to be controlled before and after the activity

\section{[Note:}

Due to limited space, Өonly data for those pairs of groups showing statistically significant differences are shown.]

\begin{tabular}{|l|l|l|l|l|}
\hline $\begin{array}{l}\text { Ways of solving } \\
\text { the problem }\end{array}$ & Groups & $\begin{array}{l}\text { Before } \\
\mathbf{( \% )}\end{array}$ & $\begin{array}{l}\text { After } \\
\mathbf{( \% )}\end{array}$ & $\begin{array}{l}\text { Changes } \\
\mathbf{( \% )}\end{array}$ \\
\hline \multirow{2}{*}{ Legislative } & HK & 68.6 & 71.6 & $\uparrow 3$ \\
\cline { 2 - 5 } & UK & 67.7 & 58.1 & $\downarrow 9.6$ \\
\hline \hline \multirow{2}{*}{ Education } & HK & 32.4 & 34.3 & $\uparrow 1.9$ \\
\cline { 2 - 5 } & UK & 6.5 & 22.6 & $\uparrow 16.1$ \\
\hline \hline \multirow{2}{*}{ Substitutes } & HK & 7.8 & 8.8 & $\uparrow 1$ \\
\cline { 2 - 5 } & UK & 6.5 & 14.5 & $\uparrow 8$ \\
\hline Breeding & HK & 7.8 & 20.6 & $\uparrow 12.8$ \\
\cline { 2 - 5 } & UK & 8.1 & 17.7 & $\uparrow 9.6$ \\
\hline
\end{tabular}

Table 4: Changes in HK and UK students' choice of ways of solving the problem 


\begin{tabular}{|l|l|l|l|l|l|}
\hline & Group & Mean & SD & t value & Cohen's d \\
\hline $\begin{array}{l}\text { Number of ways of solving } \\
\text { the problem per student } \\
\text { (Before activity) }\end{array}$ & $\begin{array}{l}\text { Junior } \\
\text { Senior }\end{array}$ & 0.92 & 0.83 & $-5.09^{* * *}$ & 0.87 \\
& & 1.85 & 1.25 & & \\
\cline { 2 - 6 } & HK Senior Female & 2.25 & 1.55 & $2.2^{*}$ & 0.74 \\
& UK Senior Female & 1.36 & 0.67 & & \\
\hline $\begin{array}{l}\text { Number of ways of solving } \\
\text { the problem per student } \\
\text { (After activity) }\end{array}$ & HK Junior Male & 1.39 & 0.99 & $2.36^{*}$ & 0.57 \\
UK Junior Male & 0.93 & 0.55 & & \\
\hline
\end{tabular}
$* \mathrm{p}<.05 ; * * * \mathrm{p}<.001$.

Table 5: Differences between different age, gender and locality groups in the range of ways of solving the problem before and after the activity

[Note:

Due to limited space, Qonly data for those pairs of groups showing statistically significant differences are shown.]

\begin{tabular}{|l|l|l|l|l|l|}
\hline & Group & Mean & SD & t value & Cohen's d \\
\hline Number of concerns per & Junior & 0.74 & 0.59 & $-3.77 * * *$ & 0.63 \\
student & Senior & 1.18 & 1.79 & & \\
(Before activity) & & & & & \\
\hline Number of concerns per & HK Junior & 1.15 & 0.81 & $3.02 * *$ & 0.6 \\
student & UK Junior & 0.69 & 0.73 & & \\
\cline { 2 - 6 } (After activity) & HK Male & 1.08 & 0.73 & $3.12 * *$ & 0.66 \\
& UK Male & 0.58 & 0.79 & & \\
\hline
\end{tabular}

$* \mathrm{p}<.05 ; * * * \mathrm{p}<.001$

Table 6: Differences between different age, gender and locality groups in the number of concerns behind their decisions before and after the activity

[Note: 
Due to limited space, Eonly data for those pairs of groups showing statistically significant differences are shown.]

\begin{tabular}{|c|c|c|c|c|c|c|}
\hline \multirow[b]{3}{*}{ Groups } & \multicolumn{4}{|c|}{ Number of Concerns per student } & \multirow[b]{3}{*}{ t Value } & \multirow[b]{3}{*}{ Cohen's d } \\
\hline & \multicolumn{2}{|l|}{ Before } & \multicolumn{2}{|l|}{ After } & & \\
\hline & Mean & $\mathrm{SD}$ & Mean & SD & & \\
\hline HK Junior & 0.8 & 0.61 & 1.15 & 0.81 & $-2.96 * *$ & 0.49 \\
\hline
\end{tabular}

Table 7: Changes in the number of concerns of HK junior students after the activity 